\title{
Reasoning of generation of threonine indispensability in humans and mammals in evolutionary aspect
}

\author{
AV Malinovsky* \\ Biophyspribor, Branch of FMBA197183 Saint Petersburg, Russia
}

\begin{abstract}
As is known, amino acid threonine is not synthesized in the vertebrates when it does not come with food. However, in the course of evolution the decomposition of threonine is changed. Taking into account that the decomposition of threonine under the action of threonine dehydratase is irreversible process, in the present work attention is focused on threonine dehydrogenase. This was done with the aim to show the inability of threonine dehydrogenase to synthesize threonine as a result of reversibility of the reaction of threonine decomposition. It is shown why threonine dehydrogenase in the tissues of mammals cannot be used in the biosynthesis of threonine. A conclusion is made that some quantity of threonine is involved in transamination.
\end{abstract}

\section{Introduction}

Protein is widely known to be of great necessity for nutrition of humans and animals. Biological value of protein is determined by its amino acid composition. Some of amino acids are indispensable, as they are not synthesized in the organism at their absence in food, while others are dispensable and can be in such a case synthesized by the organism itself. Nine amino acids (lysine, threonine, tryptophan, methionine, phenylalanine, leucine, valine, isoleucine and histidine) are of vital importance for all the investigated species of the vertebrates.

Of considerable interest is the following fact. The paper notes that after adding glycine marked as $\mathrm{N}^{15}$ to the food given to rats and rabbits, threonine did not contain this isotope marker (contrary to other amino acids, except lysine). Hence, one can conclude that threonine, like lysine, is not involved in transportation of amino groups, which is observed in other amino acids - both dispensable and indispensable [1]. Moreover, threonine being an indispensable amino acid should not be synthesized from glycine. Yet, the paper shows that after rats were given leucine marked $\mathrm{N}^{15}$, a very small number of markers was detected in threonine [2]. The fact, that some quantity of nitrogen of leucine was found in a threonine molecule, indicates availability of a minor synthesis of threonine in the organism of animals. Thus, the question arises on possibility of threonine biosynthesis in animals and humans at its absence in food, i.e. its indispensability. Research into this issue is of great significance for making a diet for the humans and for livestock.

It is necessary to withdraw at once a metabolic pathway of threonine biosynthesis catalyzed by threonine synthetase enzyme, the final stage of which is transformation of 0 - phosphor homo serine to threonine and non-organic phosphate. This enzyme is widely spread in bacteria, fungus and plants, but it does not exist in animals $[3,4]$.

\section{Threonine decomposition in the vertebrates}

The paper provides the following scheme of threonine transformation in the liver.

The work also points out, that under the influence of threonine aldolase, threonine reversibly decomposes into acetaldehyde and glycine [5,6]. Although, many reference books and textbooks on biochemistry gave much attention to both threonine aldolase and aldol cleavage in the amino acid catabolism,

M.I. Bird and P.B. Nunn were the first to doubt this [7-10]. They demonstrated that activation of threonine aldolase is homogeneously low in the rat liver and came to the conclusion, that though aldolase is present in the liver, it cannot be the main enzyme causing threonine decomposition $[10,11]$.

M.I. Bird, et al. [10] concluded that, in fact, the assumed activity of threonine aldolase results from action of threonine dehydratase and lactate dehydrogenase, with the former irreversibly decomposing threonine.

The most convincing evidence against presence of genuine threonine aldolase in the rat liver is disappearance of threonine aldolase activity in cytosolic extracts of the liver of the normally-fed and starving rats, when threonine dehydratase was removed by a specific antibody immune precipitation. Removal of dehydratase does not affect activity of allothreonine aldolase.

The results of this research explicitly show that threonine dehydratase and lactate dehydrogenase are responsible for apparent enzyme activity of «threonine aldolase».

Thus, «threonine aldolase» is not a genuine liver enzyme in mammals, and consequently, in humans. Further investigations supported existence of enzyme metabolizing allothreonine (optical isomer of threonine, noninvolved in protein composition) and, likely, its aldolase or serine hydroxyl methyl transferase, which do not

${ }^{\star}$ Correspondence to: AV Malinovsky, Biophyspribor, Branch of FMBA197183 Saint Petersburg, Russia, E-mail: info@biofizpribor.ru

Key words: threonine, NAD, acetyl- CoA, threonine dehydratase, threonine dehydrogenase

Received: October 02, 2018; Accepted: October 09, 2018; Published: October 12,2018 
affect threonine [12]. The work also confirms influence of aldolase on allothreonine rather than on threonine [13]. In the paper among the threonine catabolism pathways in the adult humans, decomposition under threonine aldolase is not mentioned at all. At the same time, there is no evidence for allothreonine to sustain the growth of mammals or to exist as natural substance, nor any evidence for threonine epimerase to be present in the mammalian liver [14-17].

If the main enzymes, contained in cytosol, of threonine decomposition in the mammalian liver until recently were supposed to be threonine dehydratase and threoninealdolase, then in mitochondria, it was threonine dehydrogenase which was regarded as such [12]. The latter catalyzes NAD- dependent oxidation of threonine to $\alpha$-aminoacetoacetic acid, which spontaneously decarboxylases converting in aminoacetone $[7,18,19]$ :

Aminoacetone later on oxidizes in the aminoacetone cycle [20]:

\section{Evidence for threonine indispensability in a comparative aspect}

The humans in the course of evolutionary process have been deprived of some of the enzymes available in mammals. This is primarily related to threonine dehydrogenase. However, if the only irreversible threonine decomposition pathway in humans under the action of threonine dehydratase cannot cause any doubts in threonine indispensability, then in mammals, the amino acid decomposition needs special examination concerning its reversibility (irreversibility) and thus, threonine indispensability.

Though the human is believed to be the latest element in the course of evolution of the vertebrates, our treatment on threonine indispensability will be started with humans, in whom it is expressed in the most evident way.

Evidence for threonine indispensability in humans: The paper points out, that $44 \%$ of threonine oxidation in babies occurs under the action of threonine dehydrogenase, whereas in adults this process makes up only $10 \%$ of the general threonine oxidation [14]. This difference due to the age, according to the work, is associated with higher metabolic need in glycine in babies as compared to that in adults [14].

The work makes comparison of genes of threonine dehydrogenase in humans with those of animals and comes to the conclusion that, as a result of evolution, the human has lost ability to synthesize threonine dehydrogenase [21].

Papers also confirm that functional threonine dehydrogenase is not available in humans because of gene mutation [22,23].

Hence, irreversible threonine decomposition under threonine dehydratase is the only pathway of threonine catabolism in humans, which is in accordance with a well-known fact, that threonine is an indispensable glycogenic amino acid and that $\alpha$-keto butyric acid is a glucose predecessor.

Evidence for threonine indispensability in mammals: M.I. Bird and P.B. Nunn in their work focused on a physiological role of the main enzymes catalyzing threonine decomposition in the mammalian liver: threonine dehydrogenase and threonine dehydratase [11]. The content of two enzymes located in different cell compartments and capability of each of them to play a dominant role in threonine catabolism in various metabolic states, puts the question of physiological functions of metabolic pathways, implemented by these two enzymes, as well as of their regulation in two various compartments.

The above-mentioned authors make assumption that the rat has a powerful physiological function of threonine/serine dehydratase to mobilize carbon of threonine (or serine) for gluconeogenesis in the liver [11]. Therefore, induction of this enzyme in the state of gluconeogenesis (where the enzyme plays a dominant role in threonine catabolism) facilitates homeostasis of blood glucose concentration at food glucose deficiency (which is the case at feeding with a high protein diet or during starvation). Alternatively, threonine dehydrogenase activity becomes prevalent at normal feeding, when need in the liver gluconeogenesis is low. Under these conditions, a physiological role of dehydrogenase activity is likely to be homeostatic for concentration of free threonine produced in decomposing of food protein.

The paper indicates that $\mathrm{pH}$ optimum for threonine dehydrogenase is 7,8 i.e. close to physiological conditions [18]. In work, measurement was made of the decarboxylation rates of $\alpha-$ amino acetoacetic acid at various $\mathrm{pH}[24]$.

8 minutes maximum half lifetime period of the acid pool in water solution was achieved at $\mathrm{pH} 0,1$ then it decreased as $\mathrm{pH}$ was raising and at $\mathrm{pH} 7$ it was less than 1 minute. Thus, such a mismatch of $\mathrm{pH}$ optima, to a great extent, makes the action on $\alpha$-amino acetoacetic acid by threonine dehydrogenase difficult for threonine reduction, even at the absence of inhibitor of the latter.

However, the paper shows that threonine dehydrogenase is inhibited by some fatty acids and their derivatives: fatty acids with a short carbon chain; $\mathrm{L}$ - and D - $\beta$ - hydroxyl butyric acid; fatty acids with a long carbon chain (lauric, myristic, palmitic and stearic); dicarboxylic acids (malonic acid and its derivatives - methyl - and hydroxyl malonic acids) [25]. Inhibition occurs at low and physiological concentrations of the compounds that are normally present and metabolized in mitochondria. In particular, mitochondria from 1 gram of the rat liver contain $66 \pm 8 \mathrm{nmol} \mathrm{L}$ - threonine and $400 \mathrm{nmol} \mathrm{D}$ - $\beta$ - hydroxyl butyric acid (molecular ratio of substrate/inhibitor is $1: 6)$. In the incubation mixture, the ratio of substrate/inhibitor equal to $166: 1$ was sufficient to attain considerable inhibition of enzyme activity ( $>50 \%)$. Hence, it is reasonable to take it for granted, that inhibitor activity in vivo can be higher than that in vitro and can even achieve a complete blocking of enzyme activity.

The publication points out, that threonine dehydrogenase inhibition by fatty acids and their derivatives facilitates directing all the available threonine through irreversible threonine dehydratase deamination to glycogenesis, which is in agreement with a well-known fact, that threonine is an indispensable glycogenic amino acid and that $\alpha$ - keto butyric acid- is a glucose predecessor [25].

The paper claims for the first time, that mouse stem cells have a highly active threonine dehydrogenase, implementing a non-typical form of threonine catabolism by decomposing it into glycine and acetyl-KoA, with glycine being instantly involved in biosynthesis of purine bases and acetyl -KoA used as an energetic substrate for Krebs cycle [26]. This issue is further discussed in papers in the process of cells differentiation, the threonine dehydrogenase activity abruptly decreases $[22,23,27]$.

The paper reports that almost all-natural amino acids (with the exception of metionin) first react with a-ketoglutaric acid in the transamination reaction to form glutamine acid and the corresponding keto acid [6]. The produced glutamine acid is then subjected to direct oxidative deamination under the action of glutamate dehydrogenase. Since both reactions (transamination and deamination of glutamine acid) are reversible, there are created conditions for synthesis, in essence, of any amino acid, if the organism has appropriate $\alpha$-keto acids. As known, the organism of animals and humans is not endowed with the 
ability to synthesize carbon skeletons ( $\alpha$-keto acids) of indispensable amino acids. Therefore, all this is closely related to threonine.

In the light of these findings, one can easily interpret the following fact: when rabbits and rats were given the diet with excess of $\mathrm{N}^{15}$ in glycine, threonine did not contain this excess: threonine cannot be formed from glycine in the vertebrates and only very insufficient quantity of glycine is subjected to transamination. At the same time, detection in threonine of $\mathrm{N},{ }^{15}$ injected into the rat with leucine, results from transamination to which leucine is subjected actively, while threonine is subjected weakly [28].

\section{Conclusion}

1) Enzyme threonine aldolase reversibly decomposes allothreonine to form glycine and acetaldehyde, but it does not influence threonine. Allothreonine is not a protein constituent and cannot convert in threonine. Hence, threonine cannot be synthesized from glycine and acetaldehyde.

2) Enzyme threonine dehydrogenase, which humans have been derived of during evolution and which is involved in decomposition of threonine in mammals, cannot be used for synthesis of the latter. Despite irreversible action of threonine dehydrogenase in vitro, this enzyme in vivo is to a great extend inhibited by fatty acids and their derivatives, which in combination with an extreme instability of physiological conditions of $\alpha$-amino acetoacetic acid makes threonine synthesis from the latter impossible.

3) Finding $\mathrm{N}^{15}$ in threonine after introducing $\mathrm{N}^{15}$-leucine into the organism speaks in favor of threonine being involved in transamination. In this case, keto derivative of threonine - $\alpha$ - keto$\beta$ - ox butyric acid - cannot be synthesized in the organism of the vertebrates either and is formed from threonine itself [29-31].

To summarize, all the above-mentioned facts are in support of impossibility of biosynthesis of threonine in the vertebrates when it does not come with food, that is, it is an indispensable amino acid for both humans and animals. Hence, threonine presence in the diet of both humans and livestock is of great necessity.

\section{References}

1. Elliott DF, Neuberger A (1950) The irreversibility of the deamination of threonine in the rabbit and rat. Biochem J 46: 207-210. [Crossref]

2. MELTZER HL, SPRINSON DB (1952) The synthesis of 4-C14, N15-L-threonine and a study of its metabolism. J Biol Chem 197: 461-474. [Crossref]

3. Garrido-Franco M, Ehlert S, Messerschmidt A, Marinkovic' S, Huber R, et al. (2002) Structure and function of threonine synthase from yeast. J Biol Chem 277: 1239612405. [Crossref]

4. Donini S, Percudani R, Credali A, Montanini B, Sartori A, et al. (2006) A threonine synthase homolog from a mammalian genome. Biochem Biophys Res Commun 350: 922-928. [Crossref]

5. Degli S, Nickolson D (1973) Metabolic pathways. The world.

6. Beresov TT, Korovkin BF (2004) Biological chemistry. Medicine.

7. Neuberger A (1981) Glycine formation from L-threonine. Comp Biochem 19: 257-303.
8. Devlin TM (1982) Textbook of Biochemistry. John Wiley and Sons, New York.

9. Leninger AL (1975) Biochemistrey. Worth Publishers, New York.

10. Bird MI, Nunn PB (1979) Measurement of L-threonine aldolase activity in rat liver [proceedings]. Biochem Soc Trans 7: 1274-1276. [Crossref]

11. Bird MI, Nunn PB (1983) Metabolic homoeostasis of L-threonine in the normally-fed rat. Importance of liver threonine dehydrogenase activity. Biochem $J$ 214: 687-694. [Crossref]

12. Yeung YG (1986) Threonine aldolase is not a genuine enzyme in rat liver. Biochem $J$ 237: 187-190.

13. Pagani R, Leoncini R, Terzuoli L, Chen J, Pizzichini M, et al. (1991) DL-allothreonine and L-threonine aldolase in rat liver. Biochem Soc Trans 19: 346S. [Crossref]

14. Darling PB, Grunov J, Rafii M, Brookes S, Ball RO, et al. (2000) Threonine dehydrogenase is a minor degratative pathway of threonine catabolism in adult humans. Am J Physiol Endocrinol Metab 278: 877-884. [Crossref]

15. West HD, Carter HE (1938) Synthesis of a - amino $-\beta-$ hydroxyl $-\mathrm{n}-$ butyric acids J Biol Chem 122: 611-617.

16. Karasek MA, Greenberg DM (1957) Studies on the properties of threonine aldolases. $J$ Biol Chem 227: 191-205. [Crossref]

17. Malkin LI, Greenberg DM (1964) Purification and properties of threonine or allothreonine aldolase from rat liver. Biochim Biophys Acta 85: 117-131. [Crossref]

18. Pagani R, Guerranti R, Leoncini R, Marinello E (1990) Activation and inhibition of rat liver L-threonine dehydrogenase. Ital J Biochem 39: 106-114. [Crossref]

19. Pagani R, Guerranti R, Righi S, Leoncini R, Vannoni D, et al. (1992) Rat liver L-threonine dehydrogenase. Biochem Soc Trans 20: 245.

20. Green ML, Elliott WH (1964) The enzymic formation of aminoacetone from threonine and its further metabolism. Biochem J 92: 537-549. [Crossref]

21. Edgar AJ (2002) The human L-threonine 3-dehydrogenase gene is an expressed pseudogene. BMC Genet 3: 18. [Crossref]

22. Han C, Gu H, Wang J, Lu W, Mei Y, et al. (2013) Regulation of L-threonine dehydrogenase in somatic cell reprogramming. Stem Cells 31: 953-965. [Crossref]

23. Winkle LJV, Gallat V, Iannaccone PM (2014) Threonine appears to be essential for proliferation of human as well as mouse embryonic stem cells. Front Cell Dev Biol 2:18. [Crossref]

24. Laver WG, Neuberger A, Scott JJ (1959) a- amino - $\beta$ - keto: acids II. Rates of decarboxylation of the free acids and the behavior of derivates on titration. Journal of the Chemikal Society 1483-1491.

25. Guerranti R, Pagani R, Neri S, Errico SV, Leoncini R, et al. (2001) Inhibition and regulation of rat liver L-threonine dehydrogenase. By different fatty acids and their derivates. Biochem and Biophys Acta 1568: 45-52. [Crossref]

26. Steven L, MeKnight D, Jlan Wang (2012) Stem cells modified to facilitate threonine catabolism.

27. Shyh-Chang N, Locasale JW, Lyssiotis CA, Zheng Y, Teo RY, et al. (2013) Influence of threonine metabolism on S-adenosylme threonine and histone methylation. Science 339: 222-226. [Crossref]

28. Beresov (1969) Amino acid exchange of normal tissues and maligner tumors. Medicine.

29. Malinovsky AV (2011) Is threonine indispensable aminoacid?. Vestnik of St. Petersburg University Ser: Biology 72-87.

30. Malinovsky AV (2012) Is threonine indispensable amino acid for birds?. Vestnik of St Petersburg University. Ser: Biology 60-65

31. Malinovsky AV (2001) Is threonine indispensable amino acid for human?. Preventive and Clinical Medicine 4: 116-119.

Copyright: (C2018 Malinovsky AV. This is an open-access article distributed under the terms of the Creative Commons Attribution License, which permits unrestricted use, distribution, and reproduction in any medium, provided the original author and source are credited. 